\title{
Air pollution impacts on human health and policies to reduce air pollution
}

\author{
M. R. Karliansyah
}

Check for updates

The impact of air pollution on human health represents a serious public health crisis across Asia. Air pollution is well-recognized as an important risk factor for global disease burdens and has a major impact on human health, particularly among the vulnerable person, such as elder and children. Annually, 7 million premature deaths worldwide and 215.5 million disabilityadjusted life years are attributable to exposure to ambient and indoor air pollution.

Until 2035, the projected population growth in Indonesia will increase to 305,652,400. The rapid growth of population will also increase the number of industries and transportation. Based on research from the Cost-Benefit Analysis Fuel Economy Initiative Indonesia 2012, the growth of cars was 1.3 million units per year and the growth of motorbikes was double the growth of cars. The growth of manufacturing, oil and gas, and agro-industries has increased every year both in terms of production and the number of industries. The increasing growth of industries and transportation will also increase ambient air pollution. Furthermore, other contributors to pollution in Indonesia are forest and land fires.

To provide information to the public regarding the status of ambient air quality, the Ministry of Environment and Forestry (MoEF) Republic of Indonesia has monitored an ambient air quality through 26 automatic air quality monitoring stations spread throughout Indonesia. To provide an ease and uniformity of ambient air quality information to the community at a certain location and time, the results of air quality monitoring are delivered into pollutant standard index (PSI). The PSI is a type of air quality index, which is a number used to indicate the level of pollutants in air delivered by averaging data collected for the past 24 hours. Related to health, the Ministry of Health, Republic of Indonesia issued Minister of Health Decree No. 289/2013 on "The impact of air pollution control procedures due to forest fires on health" which describes the security measures of forest fire danger based on PSI.

According to the data of 26 accumulated air quality monitoring stations from 2017 to 2019, 74\% of Indonesia's ambient air status is in good category, $16 \%$ moderate, $2 \%$ unhealthy, $0.2 \%$ very unhealthy, and $0.21 \%$ hazardous. In 2019, forest fires have occurred in several provinces of Sumatera and Kalimantan. These regions possess large areas of peatland, which is highly combustible during the dry season. From Figure 1, Jambi, Palembang, Palangkaraya, Pekanbaru, and Pontianak have experienced a poor air quality (very unhealthy and hazardous) caused by forest fires. Some cities near that forest fires such as Aceh and Batam were also affected. The information of air quality conditions is given to the public as an early warning system. The impact of air quality that has been measured is grouped by index values and descriptors (Table 1), explaining the effects of the levels according to Minister of Health Decree No. 289/2013 on "The impact of air pollution

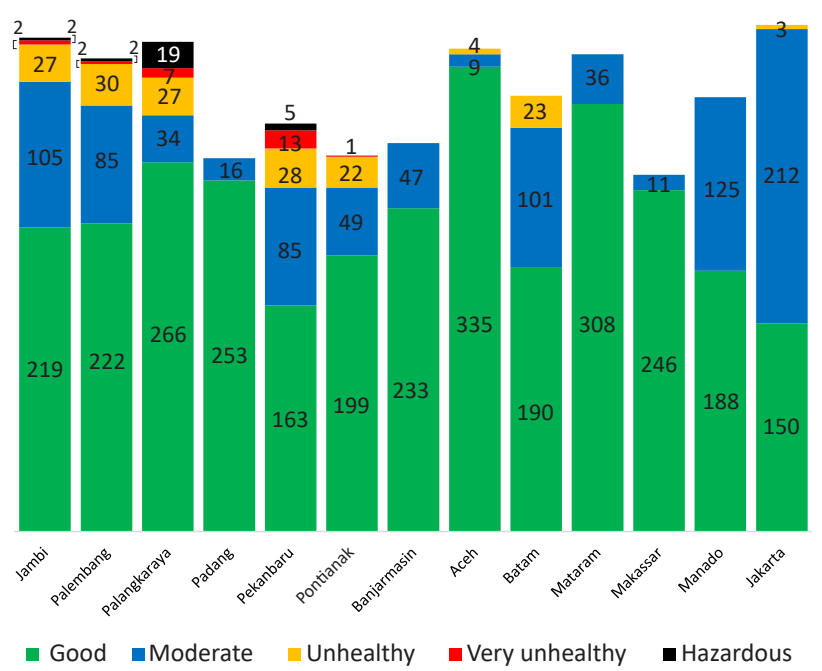

Figure 1. Pollutant standard index data in 2019 
Table 1. PSI indicator

\begin{tabular}{|c|c|c|}
\hline PSI & Descriptor & Health effects \\
\hline $0-50$ & Good & $\begin{array}{l}\text { In this condition, air quality does not have a negative impact on health. Neither the pollutant } \\
\text { components such as carbon monoxide, particulates nor nitrogen have a significant impact on health. } \\
\text { You could say the air quality in this number is healthy for the respiratory system. }\end{array}$ \\
\hline 51-100 & Moderate & $\begin{array}{l}\text { Quoting the data and information center of the Ministry of Health of the Republic of Indonesia in } \\
2015 \text {, moderate category did not have an impact on health. But in terms of contamination in the } \\
\text { form of particulates, there could be a decrease in visibility. }\end{array}$ \\
\hline $101-200$ & Unhealthy & $\begin{array}{l}\text { If the PSI number indicates } 101-199 \text {, it means that health impacts can arise. Air quality with the } \\
\text { category of "Unhealthy" can cause irritation to the airways. For those who have heart disease, } \\
\text { symptoms can get worse. }\end{array}$ \\
\hline 201-300 & Very unhealthy & $\begin{array}{l}\text { Air quality like this can trigger symptoms in those who have ARI, pneumonia, heart disease, asthma, } \\
\text { and bronchitis. }\end{array}$ \\
\hline $301+$ & Hazardous & $\begin{array}{l}\text { At numbers } 300-399 \text {, those who already have respiratory and heart problems will experience more } \\
\text { severe symptoms. Whereas those who are healthy, will feel easily tired and experience breathing } \\
\text { problems such as coughing, sore throat, uncomfortable breathing, and also eye irritation due to } \\
\text { dust particles. Then at }>400 \text {, the condition is very dangerous for everyone especially the vulnerable } \\
\text { groups such as toddlers, pregnant women, the elderly and people with respiratory problems. } \\
\text { Outdoor activities are not allowed at all, and vulnerable groups were immediately evacuated to the } \\
\text { air pollution free space. }\end{array}$ \\
\hline
\end{tabular}

PSI=pollutant standard index; $\mathrm{ARI}=$ acute respiratory infection

control procedures due to forest fires on health" which describes the security measures of forest fire danger based on PSI.

MoEF Republic of Indonesia through the Directorate of Air Pollution Control already implemented Euro 4: MoEF regulation No. 20/2017 for the quality standard of exhaust gas emission for all motor vehicles of new types in $\mathrm{M}, \mathrm{N}$, and $\mathrm{O}$ categories to reduce air pollution levels. This policy changes the previous policy which used Euro 4 standard for exporting car only. However, domestic area of Indonesia still permits the use of Euro 2 for diesel vehicles until 2021.

In 2019, MoEF Republic of Indonesia already tightened emission standard to improve ambient air quality by making a regulation for quality standard/ company standard in producing emissions, especially for power plant (MoEF regulation No. 15/2019) and fertilizer industries (MoEF regulation No. 17/2019) that have significant portion of particulate matter and $\mathrm{SO}_{2}$ emissions. Besides, we are working with the companies involved in these industries to reduce their emissions by encouraging technical and processing changes to reduce emissions for energy and industrial source to help us achieve our targets for cleaner air.

Forest fire preventions were done by cooperating with central and local governments; the army and the police integrated patrol; air operations which include air patrols, water bombing, making artificial rain, weather modification; and land operations which include independent patrols and early fire extinction. Law enforcement efforts and real-time air quality monitoring equipment installation were also carried out. Furthermore, all stakeholders have to work together to improve ambient air quality and make a sustainable action plan to manage air quality starting from monitoring air quality continuously, making air quality information accessible to the public, and reducing emissions from industries and vehicles.

From Directorate General of Pollution and Environmental Damage Control, Ministry of Environment and Forestry, Jakarta, Indonesia pISSN: 0853-1773 • elSSN: 2252-8083

https://doi.org/10.13181/mji.com.204579

Med J Indones. 2020;29:6-7

\section{Corresponding author:}

M. R. Karliansyah

E-mail: dirjenppkl@gmail.com

\section{REFERENCES}

1. The United Nations Environment Programme (UNEP). Summary air pollution in Asia and the Pacific: science-based solutions. 2019. Bangkok: The United Nations Environment Programme (UNEP); 2019. p. 1-58. 